\title{
Economic scheme for designing Skip lot sampling plans involving Cost functions using Graphical Evaluation Review Technique
}

\author{
K. Pradeepa Veerakumari ${ }^{1 *}$, M. Kokila ${ }^{2}$ \\ ${ }^{1}$ Department of Statistics, Bharathiar University, Coimbatore, Tamil Nadu, India \\ ${ }^{2}$ Department of Statistics, Bharathiar University, Coimbatore, Tamil Nadu, India \\ *Corresponding Author: bayestat@yahoo.com, Tel.:09443937722
}

Available online at: www.isroset.org

Received: 30/May/2018, Revised: 11/Jun/2018/2018, Accepted: 20/Jun/2018, Online: 30/Jun/2018

Abstract-The main thrust of this paper is to design optimum cost procedure for skip lot sampling plan of type SkSP-2 and SkSP-3 with single sampling as reference plan using GERT techniques. This favors producer as well as consumer. Simulation has been done and tables are constructed for various iterations of parameters of SkSP-2 and SkSP-3 with single sampling plan.

Keywords- SkSP-2, SkSP-3, Graphical Evaluation Review Technique, Optimum cost, Single sampling plan

\section{INTRODUCTION}

Acceptance sampling has been widely gained application in industry since the period of Dodge and Romig [4]. The purpose for which sampling inspection is applied varies from situation to situation. In some production processes, the formation of discrete lots is not possible among the successive flow of products. The inspection along this flow is performed on individual unit is the continuous sampling plan designated as CSP-1 by Dodge [5]. The continuous sampling approach may be utilized to an individual lot received in a steady stream of production is the skip-lot sampling plan SkSP-1 introduced by Dodge [6] and then Dodge and Perry [7] developed SkSP-2 in which the producer's risk and consumer's risk has been factored into skip-lot procedure using standard reference plan. Soundararajan and Vijayaraghavan [24] proposed a new system of SkSP-3 under the skip-lot sampling inspection plan. Vijayaraghavan [25] has designed and evaluated the SkSP-3 plan.

Ohta and Kase [14] determine the testing sequence which minimizes the average total cost using GERT analysis. Chakraborty and Rathie [2] studied inspection system influenced by error through GERT and various costs associated with CSP-1, CSP-2 and CSP-3 had been given. Chen and Chou [3] determine the minimum total expected cost per unit produced under Cassady et al. model for CSP-1. Haji and Haji [10] states that either a $100 \%$ inspection or random inspection should be adopted on continuous production to minimize the average unit cost.

Lin [12] determines the optimum policy of CSP-T with return cost using GERT approach. Balamurali and Jun [1] has given an economic design for SkSP-V in which the cost is lower under the SkSP-V. Pradeepa Veerakumari and Resmi [18] designed optimum plan parameters for CSP-2 through GERT analysis. Vispute and Singh [26] developed an economic acceptance sampling plan for variables under the method of second order auto correlation. Haji and Haji [10] have been motivated to develop this study based on optimum cost for the skip lot sampling plan. The present study elaborates the structural network which has its stochastic nature is developed for this skip-lot sampling plan-2 (SkSP-2) and SkSP-3 with the Graphical Evaluation Review Technique (GERT) helps in inspection reduction and also economically optimal.

The Rest of this paper is organized as follows. In the next Section II the definitions and brief note are described. Section III contains the methodology, Expressions, some measures and notations; Section IV contains numerical illustration, results and discussion to obtain the optimal solution with respect to the parameter of the plan. Section V presents the conclusion of research work with future directions. Further this paper is expressed in figures and tables. 


\section{DEFINITIONS AND BRIEF NOTE}

\section{Graphical Evaluation Review Technique (GERT):}

The GERT was introduced by Pritsker [20]. Several contributors introduce procedures for various sampling plan in order to obtain optimum policy. Kase and Ohta [15] analyze the dynamics of Dodge-Romig sampling inspection plan. Gauri Shankar and Mohapatra [22] analyzed Dodge's CSP-1 through GERT approach which is a visual dynamic representation of the flow of the inspection network and it tells the thorough characterization of the sampling plan. The network alternates between screening inspection and fraction of sampling. The network activity embodies with logical nodes and directed branches. The probability of the branch, $\varphi$ of the network is where it emanates from the node. The moment generating function specifies distribution and the expectation of a function of random variables cost $\mathrm{C}$ and $\mathrm{i}$. The cost $\mathrm{C}$ associated with a network is characterized by the moment generating function of the form $\mathrm{M}_{\mathrm{C}}(\theta)$ $=\sum_{\mathrm{c}} \exp (\mathrm{C} \theta) \cdot \mathrm{f}(\mathrm{C})=\mathrm{W}(\mathrm{C}) / \mathrm{P}($ transition states $)$. The w-function is a key factor which gives information about the sequence of operations obtained by the relationship between these nodes. The w-function is by multiplying the moment generating function with the probability of the respective branch. W(C) $=\varphi \cdot M_{C}(\theta)$. Also the Moment generating function is in terms of number of lots passed. $\mathrm{W}(\mathrm{i})=\mathrm{P} \cdot \mathrm{M}_{\mathrm{i}}(\theta)=\mathrm{Pe}^{\theta}$. The variability in the costs has been ascertained in the section 3 .

\section{Methodology AND Measures}

\section{Evaluation of parameters of SkSP-2with SSP using GERT:}

Perry [17] gave the operating procedure of SkSP-2 as,

i) Start with normal inspection of each lot using the reference plan.

ii) When $\mathrm{i}$ consecutive lots are found conformity to standards, then switch to skipping inspection (inspecting only $f$ of lots) using the reference plan.

iii) If any lots are found non conformance on skipping inspection then a lot is rejected, switch to normal inspection. Otherwise continue the skipping inspection using the reference plan and accept the lot.

iv) The rejected lots are replaced by the good ones and revert to $100 \%$ inspection under step (i). The termination of inspection is happens, when the lot is found clear of defects. The probability of acceptance under Poisson model for the single sampling plan is given by

$\mathrm{P}=\sum_{\mathrm{x}=0}^{\mathrm{c}} \frac{\mathrm{e}^{-\mathrm{np}_{\mathrm{np}} \mathrm{x}}}{\mathrm{x} !} ; \mathrm{x}=0,1,2 \ldots \infty$

The probability $\mathrm{P}$ that the network branch, is realized and the number of lots is associated with the activity performed is represented by the branch.

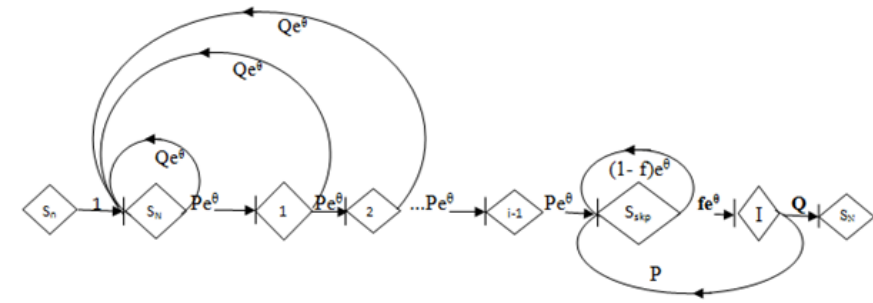

Figure 1. GERT network of SkSP-2 under normal inspection (100\% inspection) and partial inspection (sampling fraction)

The Figure 1 shows the Skip-lot sampling system-2 under screening inspection for one inspection cycle is expressed as,

$$
\begin{gathered}
W_{S_{N} k p}(\theta)=\frac{\left(P e^{\theta}\right)^{i}}{1-\left(Q e^{\theta}\left[1+P e^{\theta}+\left(P e^{\theta}\right)^{2}+\cdots+P^{i-1} e^{(i-1) \theta}\right]\right)} \\
W_{S_{N s k p}}(\theta)=\frac{\left(P e^{\theta}\right)^{i}\left(1-P e^{\theta}\right)}{1-P e^{\theta}-Q e^{\theta}+P e^{\theta}\left(Q e^{\theta}\right)^{i}}
\end{gathered}
$$

The probability realization of $100 \%$ inspection is

$$
P_{S_{N s k p}}(\theta)=\left[W_{S_{N} k p}(\theta)\right]_{\theta=0}=1
$$

Therefore $W_{S_{N} s k p}(\theta)=M_{S_{N} s k p}(\theta)$

and the average number of inspection as Perry [17] in screening inspection for SkSP-2 during one inspection cycle is

$$
\begin{aligned}
& \mathrm{U}=\left[\frac{\left(d M_{S_{N} s k p}(\theta)\right.}{d \theta}\right]_{\theta=0}=\frac{1-P^{i+1}-P^{i}+P^{i+1}}{P^{i} Q} \\
& \mathrm{U}=\frac{1-P^{i}}{P^{i}(1-P)}
\end{aligned}
$$

The Figure 1 depicts the SkSP-2 under sampling fraction one inspection cycle is expressed as,

$$
W_{S_{s k p} T}(\theta)=\frac{f Q e^{\theta}}{1-(1-f) e^{\theta}-(1-Q) f e^{\theta}}
$$

The probability realization of sampling inspection is

$P_{S_{\text {Skp } T}}(\theta)=\left[W_{S_{\text {skp } T}}(\theta)\right]_{\theta=0}=1$

Thus, $W_{S_{\text {skp } T}}(\theta)=M_{S_{\text {skp }}}(\theta)$

Then differentiating $M_{S_{\text {skp } T}}(\theta)$, we get

$$
\begin{gathered}
{\left[\frac{\left(d M_{S_{S k p T}}(\theta)\right.}{d \theta}\right]_{\theta=0}=\frac{f Q e^{\theta}}{1-(1-f) e^{\theta}-(1-Q) f e^{\theta}}} \\
\mathrm{V}=\frac{f Q}{Q^{2} f^{2}}=\frac{1}{f(1-P)}
\end{gathered}
$$

is the average number of lots passed under sampling fraction on one inspection cycle.

Hence the Average fraction of lots inspected over long run is

$$
\mathrm{F}=\frac{U+f V}{U+V}=\frac{f}{(1-f) P^{i}+f}
$$

\section{Glossary and Notations:}

$\mathrm{S}_{0}=$ Initial state of the sampling plan.

$\mathrm{S}_{\mathrm{N}}=$ Start with Normal inspection.

$\mathrm{S}_{\mathrm{skp}}=$ Switch to Skipping inspection.

$\mathrm{T}=$ Transition to normal inspection.

$\mathrm{P}=$ Probability of acceptance under reference plan, $\mathrm{Q}=1-\mathrm{P}$

$\mathrm{i}=$ Number of lots to be inspected.

$\mathrm{f}=$ fraction of lots to be inspected in the skipping inspection.

$\mathrm{U}=$ Average number of lots inspected under normal inspection. 
$\mathrm{V}=$ Expected number of lots passed under sampling fraction.

$\mathrm{C}=$ cost associated with the stochastic branch.

$\mathrm{c}_{1}=$ Inspection cost of one product.

$c_{2}=$ Cost of defective product returned by the customer.

$\mathrm{c}_{3}=$ Reworking or replacing cost for one defective product.

$\mathrm{E}(\mathrm{C})=$ Average cost for one inspection cycle.

$\mathrm{E}(\mathrm{L})=$ Expected amount of lots in an inspection cycle.

The Possible states for SkSP-2 inspection system can be defined as,

$\mathrm{S}_{\mathrm{N}}=$ Start with normal inspection of i clearance number of lots, using the single sampling plan as the reference plan.

In the case of SkSP-3 if a defective is found in f, continue with $\mathrm{k}$ reduced clearance number of lots.

$\mathrm{S}_{\mathrm{skp}}=$ Transition to Skipping inspection is in effect.

$\mathrm{T}=$ Transition to normal inspection.

\section{Designing of Optimum Cost Model for various Skip lot Sampling Plans:}

When the average sample number increases, the total cost of inspection on a product also increases. In order to inexpensively save the cost for the producer considering both the risks the GERT technique has been employed. Based on the work Haji [10] and Lin [12] the cost model has been developed for Skip-lot sampling plan-2 and SkSP3. Here instead of considering chance of inspection error the reference plan of single sampling plan has been initiated with the confidence level not less than $1-\alpha$. This allow to proceed the inspection further satisfying the condition,

$\mathrm{P}_{\mathrm{a}}\left(\mathrm{p}_{1}\right) \geq 1-\alpha$

$\mathrm{P}_{\mathrm{a}}\left(\mathrm{p}_{2}\right) \leq \beta$

Let $\mathrm{z}$ be the number of units produced and the cost involves inspection cost of one unit, defective unit returned by the customer, incoming defective (quality) and the rework or replacing cost of a product. Then from the renewal process by Ross [21] the steady state average unit cost of sampling plan in terms of $i$ and $f$ can be written as

$\mathrm{C}(\mathrm{i}, \mathrm{f})=\lim _{z \rightarrow \infty} \frac{E(z)}{z}=\frac{E(\text { cost during the inspection cycle })}{E(\text { length of a cycle })}$

The nature of the $\mathrm{C}(\mathrm{i}, \mathrm{f})$ is expressed as,

$\delta \mathrm{C}(\mathrm{i}, \mathrm{f})=\mathrm{C}\left(\mathrm{i}, \mathrm{f}^{(1)}\right)-\mathrm{C}\left(\mathrm{i}, \mathrm{f}^{(0)}\right)$ for 'fixed $\mathrm{i}$ and $\mathrm{f}$ varies according to Haji [10].

$\delta \mathrm{C}(\mathrm{i}, \mathrm{f})=\frac{f^{(1)}\left(\mathrm{c}_{1}+\mathrm{pc}_{3}\right)+P^{i} P\left[\mathrm{c}_{2}\left(1-\mathrm{f}^{(1)}\right)\right]}{f^{(1)}-f^{(1)} P^{i}+P^{i}}-\frac{f^{(0)}\left(\mathrm{c}_{1}+\mathrm{pc}_{3}\right)+P^{i} P\left[\mathrm{c}_{2}\left(1-\mathrm{f}^{(0)}\right)\right]}{f^{(0)}-f^{(0)} P^{i}+P^{i}}$

The partial inspection in which each lot is inspected with probability of acceptance $\mathrm{P}(\geq 0.95)$ is optimal as $\delta \mathrm{C}(\mathrm{i}, \mathrm{f})>0$ depends on the values of $c_{1}, c_{2}, c_{3}$ and $p$.

\section{Average total inspection Model for SkSP-2:}

The term $\mathrm{U}$ and $\mathrm{V}$ can be taken without using their actual values applying Mason's rule. The w-function is in terms of number of lots at both stages for one inspection cycle as $W s_{N \operatorname{skp} T}(\theta)=\mathrm{e}^{\mathrm{U} \theta} \cdot \mathrm{e}^{\mathrm{V} \theta}=\mathrm{e}^{(\mathrm{U}+\mathrm{V}) \theta}$
The probability of network realization is given by

$P S_{N \operatorname{skp} T}(\theta)=\left[W s_{N \operatorname{skp} T}(\theta)\right]_{\theta=0}=1$

Thus, $M s_{N \operatorname{skp} T}(\theta)=\frac{W_{S_{N s k p T}(\theta)}}{\mathrm{P}_{S_{N s k p}}}=\mathrm{e}^{(\mathrm{U}+\mathrm{V}) \theta}$

The expected length of each cycle during normal inspection and skipping inspection is the total number of lots inspected,

$$
\begin{aligned}
& \mathrm{E}(\mathrm{L})=\left[\frac{d M_{S_{N s k p T}}(\theta)}{d \theta}\right]_{\theta=0}=\mathrm{U}+\mathrm{V} \\
& \mathrm{E}(\mathrm{L})=\frac{1-P^{i}}{P^{i}(1-P)}+\frac{1}{f(1-P)}
\end{aligned}
$$

\section{Cost Model for SkSP-2:}

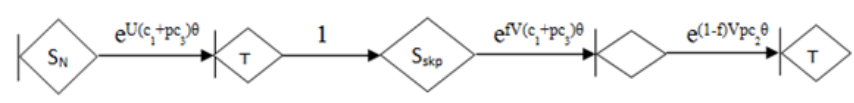

Figure2. Cost Model for Skip-lot sampling plan-2 and SkSP-3

Figure 2 describes various costs associated with a skip-lot sampling plan-2 expressed in the w-function from the start to the end of the inspection.

The moment generating function of cost $\mathrm{C}$ if $\mathrm{M}_{\mathrm{C}}(\theta)=\mathrm{e}^{\mathrm{C} \theta}$

where $C$ and $\theta$ is a real variable.

Thus various costs associated is expressed in the w-function from the beginning to the end of the inspection of the lot as,

$W S_{N \operatorname{skp} T}(\theta)=\mathrm{e}_{1}^{\mathrm{U}(\mathrm{c}+\mathrm{pc}) \theta} \cdot \mathrm{e}_{1}^{\mathrm{fV}(\mathrm{c}+\mathrm{pc}) \theta} \cdot \mathrm{e}_{3}^{(1-\mathrm{f}) \mathrm{Vpc} \theta}$

The probability of network realization is

$P S_{N \text { skp T }}(\theta)=\left[W S_{N \operatorname{skp} T}(\theta)\right]_{\theta=0}=1$

Thus, $M S_{N \text { skp T }}(\theta)=\frac{W_{S_{N s k p T}(\theta)}}{P S_{N \text { skpT }}(\theta)}=W_{S_{N s k p T}(\theta)}$

Further, the expected total cost of each inspection cycle for SkSP-2 is

$\mathrm{E}(\mathrm{C})=\left[\frac{\left(d M_{S_{N s k p T}}(\theta)\right.}{d \theta}\right]_{\theta=0}=(\mathrm{U}+\mathrm{fV})\left(\mathrm{c}_{1}+\mathrm{pc}_{3}\right)+\mathrm{pc}_{2}(1-\mathrm{f}) \mathrm{V}$
$\mathrm{E}(\mathrm{C})=\left(\mathrm{c}_{1}+\mathrm{pc}_{3}\right)\left\{\frac{1-P^{i}}{P^{i}(1-P)}+\frac{1}{(1-P)}\right\}+\mathrm{pc}_{2}(1-\mathrm{f}) \frac{1}{f(1-P)}$

and the variances $\mathrm{V}(\mathrm{C})$ of the cost $\mathrm{C}$ are from the start of the inspection to the delivery of a lot.

$\begin{aligned} \mathrm{V}(\mathrm{C})= & \left\{\frac{\left(d^{2} M_{S_{N} s k p T}(\theta)\right.}{d^{2} \theta}\right\}_{\theta=0}-\left\{\frac{\left(d M_{S_{N} s k p T}(\theta)\right.}{d \theta}\right\}_{\theta=0}^{2} \\ = & \left\{\left(\mathrm{c}_{1}+\mathrm{pc}_{3}\right)\left\{\frac{1-P^{i}}{P^{i}(1-P)}+\frac{1}{(1-P)}\right\}+\mathrm{pc}_{2}(1-\mathrm{f}) \frac{1}{f(1-P)}\right\}^{2}- \\ & \left\{\left(\mathrm{c}_{1}+\mathrm{pc}_{3}\right)\left\{\frac{1-P^{i}}{P^{i}(1-P)}+\frac{1}{(1-P)}\right\}+\mathrm{pc}_{2}(1-\mathrm{f}) \frac{1}{f(1-P)}\right\}^{2}\end{aligned}$

The ASN, C $(\mathrm{i}, \mathrm{f})$ has been simulated and provided in Table 1 and Table 2 for various values of $i$ and $f$.

Table. 1 Optimum cost and ASN using SkSP-2 when $i=4, n=20, c=1$ 


\begin{tabular}{|c|c|c|c|c|c|c|c|}
\hline $\mathrm{p}$ & $\mathrm{P}$ & $\begin{array}{c}\text { ASN } \\
\mathrm{f}=1 / 2\end{array}$ & $\mathrm{C}(\mathrm{i}, \mathrm{f})$ & $\begin{array}{c}\text { ASN } \\
\mathrm{f}=1 / 3\end{array}$ & $\mathrm{C}(\mathrm{i}, \mathrm{f})$ & $\begin{array}{c}\text { ASN } \\
\mathrm{f}=1 / 4\end{array}$ & $\mathrm{C}(\mathrm{i}, \mathrm{f})$ \\
\hline 0.00002 & 0.999 & 10 & 0.013 & 6 & 0.008 & 5 & 0.006 \\
\hline 0.0001 & 0.999 & 10 & 0.013 & 6 & 0.008 & 5 & 0.006 \\
\hline 0.002 & 0.999 & 10 & 0.019 & 6 & 0.012 & 5 & 0.010 \\
\hline 0.003 & 0.998 & 10 & 0.022 & 6 & 0.014 & 5 & 0.012 \\
\hline 0.004 & 0.997 & 10 & 0.025 & 6 & 0.016 & 5 & 0.014 \\
\hline 0.005 & 0.995 & 10 & 0.028 & 6 & 0.019 & 5 & 0.016 \\
\hline 0.006 & 0.993 & 10 & 0.03 & 6 & 0.021 & 5 & 0.019 \\
\hline 0.010 & 0.983 & 10 & 0.04 & 6 & 0.03 & 5 & 0.036 \\
\hline 0.011 & 0.979 & 10 & 0.047 & 6 & 0.033 & 5 & 0.029 \\
\hline 0.012 & 0.975 & 11 & 0.05 & 6 & 0.035 & 5 & 0.032 \\
\hline 0.013 & 0.972 & 11 & 0.053 & 7 & 0.038 & 6 & 0.034 \\
\hline 0.015 & 0.963 & 11 & 0.06 & 7 & 0.043 & 6 & 0.039 \\
\hline 0.017 & 0.954 & 11 & 0.07 & 7 & 0.049 & 6 & 0.044 \\
\hline 0.018 & 0.949 & 11 & 0.072 & 7 & 0.051 & 5 & 0.046 \\
\hline
\end{tabular}

Table.2 Optimum cost and ASN using SkSP-2 when i=4, n=20, c=1

\begin{tabular}{|c|c|c|c|c|c|}
\hline $\mathrm{p}$ & $\mathrm{P}$ & $\begin{array}{c}\text { ASN } \\
\mathrm{f}=1 / 5\end{array}$ & $\mathrm{C}(\mathrm{i}, \mathrm{f})$ & $\begin{array}{c}\text { ASN } \\
\mathrm{f}=1 / 10\end{array}$ & $\mathrm{C}(\mathrm{i}, \mathrm{f})$ \\
\hline 0.00002 & 0.999 & 4 & 0.005 & 2 & 0.003 \\
\hline 0.0001 & 0.999 & 4 & 0.005 & 2 & 0.003 \\
\hline 0.002 & 0.999 & 4 & 0.009 & 2 & 0.005 \\
\hline 0.003 & 0.998 & 4 & 0.010 & 2 & 0.007 \\
\hline 0.004 & 0.997 & 4 & 0.012 & 2 & 0.008 \\
\hline 0.005 & 0.995 & 4 & 0.014 & 2 & 0.009 \\
\hline 0.006 & 0.993 & 4 & 0.016 & 2 & 0.011 \\
\hline 0.010 & 0.983 & 4 & 0.024 & 2 & 0.017 \\
\hline 0.011 & 0.979 & 4 & 0.026 & 2 & 0.018 \\
\hline 0.012 & 0.975 & 4 & 0.028 & 2 & 0.019 \\
\hline 0.013 & 0.972 & 4 & 0.029 & 2 & 0.022 \\
\hline 0.015 & 0.963 & 4 & 0.034 & 2 & 0.024 \\
\hline 0.017 & 0.954 & 5 & 0.039 & 2 & 0.028 \\
\hline 0.018 & 0.949 & 5 & 0.041 & 2 & 0.030 \\
\hline
\end{tabular}

The long run minimum average unit cost subject to $i$ and $f$ is given by

$\mathrm{C}(\mathrm{i}, \mathrm{f})=\frac{E(C)}{E(L)}=\frac{\left(\mathrm{c}_{1}+\mathrm{pc}_{3}\right)\left\{\frac{1-P^{i}}{P^{i}(1-P)}+\frac{1}{(1-P)}\right\}+\mathrm{pc}_{2}(1-\mathrm{f}) \frac{1}{f(1-P)}}{\frac{1-P^{i}}{P^{i}(1-P)}+\frac{1}{f(1-P)}}$

\section{Average total inspection Model for SkSP-3:}

The term U and V can be taken applying Mason's rule [13].

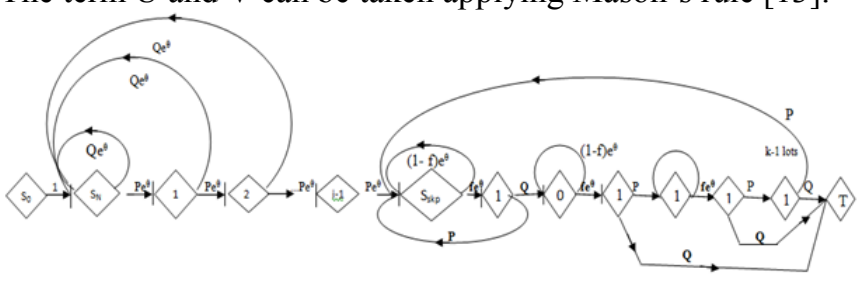

Figure4. GERT network of SkSP-3 under normal inspection and partial inspection

Figure 4 shows the w-function is in terms of number of lots at each stage for one inspection cycle as,

$W s_{N \text { skp T }}(\theta)=\mathrm{e}^{\mathrm{U} \theta} \cdot \mathrm{e}^{\mathrm{V} \theta}=\mathrm{e}^{(\mathrm{U}+\mathrm{V}) \theta}$

The probability of network realization is given as

$$
P S_{N \operatorname{skp} T}(\theta)=\left[W s_{N \operatorname{skp} T}(\theta)\right]_{\theta=0}=1
$$

Thus,

$$
M S_{N \operatorname{skp} T}(\theta)=\frac{W_{S_{N} \operatorname{skp} T^{(\theta)}}}{\mathrm{P}_{S_{N} \operatorname{skp} T}}=\mathrm{e}^{(\mathrm{U}+\mathrm{V}) \theta}
$$

The expected length of each cycle during normal inspection and skipping inspection is the total number of lots inspected,

$$
\begin{aligned}
& \mathrm{E}(\mathrm{L})=\left[\frac{d M_{S_{N s k p T}}(\theta)}{d \theta}\right]_{\theta=0}=\mathrm{U}+\mathrm{V} \\
& \mathrm{E}(\mathrm{L})=\frac{\left(1-P^{i}\right)}{Q P^{i}}+\frac{\left(2-P^{k}\right)}{f Q\left(1-P^{k}\right)}
\end{aligned}
$$

\section{Cost Model for SkSP-3:}

Figure 2 shows various costs associated with a skip-lot sampling plan-3 expressed in the w-function from the start to the end of the inspection.

The moment generating function of $\operatorname{cost} \mathrm{C}$ is $\mathrm{M}_{\mathrm{C}}(\theta)=\mathrm{e}^{\mathrm{C} \theta}$

Further, the expected total cost of each inspection cycle for SkSP-3 is

$$
\begin{aligned}
& \mathrm{E}(\mathrm{C})=\left[\frac{\left(d M_{S_{N S k p T}}(\theta)\right.}{d \theta}\right]_{\theta=0}=(\mathrm{U}+\mathrm{fV})\left(\mathrm{c}_{1}+\mathrm{pc}_{3}\right)+\mathrm{pc}_{2}(1-\mathrm{f}) \mathrm{V} \\
& \mathrm{E}(\mathrm{C})=\left(\mathrm{c}_{1}+\mathrm{pc}_{3}\right)\left\{\frac{\left(1-P^{i}\right)}{Q P^{i}}+\frac{\left(2-P^{k}\right)}{Q\left(1-P^{k}\right)}\right\}+\mathrm{pc}_{2}(1-\mathrm{f}) \frac{\left(2-P^{k}\right)}{f Q\left(1-P^{k}\right)}
\end{aligned}
$$

and the variance $\mathrm{V}(\mathrm{C})$ of the cost $\mathrm{C}$ is from the start of the inspection to the delivery of a lot.

$\mathrm{V}(\mathrm{C})=\left\{\frac{\left(d^{2} M_{S_{N} s k p T}(\theta)\right.}{d^{2} \theta}\right\}_{\theta=0}-\left\{\frac{\left(d M_{S_{N} s k p T}(\theta)\right.}{d \theta}\right\}_{\theta=0}^{2}$ 
$=\left\{\left(\mathrm{c}_{1}+\mathrm{pc}_{3}\right)\left\{\frac{\left(1-P^{i}\right)}{Q P^{i}}+\frac{\left(2-P^{k}\right)}{Q\left(1-P^{k}\right)}\right\}+\mathrm{pc}_{2}(1-) \frac{\left(2-P^{k}\right)}{f Q\left(1-P^{k}\right)}\right\}^{2}-$

$\left\{\left(\mathrm{c}_{1}+\mathrm{pc}_{3}\right)\left\{\frac{\left(1-\mathrm{P}^{\mathrm{i}}\right)}{\mathrm{QP}^{\mathrm{i}}}+\frac{\left(2-\mathrm{P}^{\mathrm{k}}\right)}{\mathrm{Q}\left(1-\mathrm{P}^{\mathrm{k}}\right)}\right\}+\mathrm{pc}_{2}(1-\mathrm{f}) \frac{\left(2-\mathrm{P}^{\mathrm{k}}\right)}{\mathrm{fQ}\left(1-\mathrm{P}^{\mathrm{k}}\right)}\right\}^{2}$

Thus the distribution of the cost $\mathrm{C}$ is degenerate distribution as their variance is zero. It implies that the variability of the cost is constant throughout the inspection under SkSP-2 and SkSP-3. The long run minimum average unit cost subject to $\mathrm{i}, \mathrm{k}$ and $\mathrm{f}$ is given by

$\mathrm{C}(\mathrm{i}, \mathrm{f})=\frac{E(C)}{E(L)}=\frac{(\mathrm{c} 1+\mathrm{pc} 3)\left\{\frac{\left(1-P^{i}\right)}{Q P^{i}}+\frac{\left(2-P^{k}\right)}{Q\left(1-P^{k}\right)}\right\}+\mathrm{pc} 2(1-\mathrm{f}) \frac{\left(2-P^{k}\right)}{f Q\left(1-P^{k}\right)}}{\frac{\left(1-P^{i}\right)}{Q P^{i}}+\frac{\left(2-P^{k}\right)}{f Q\left(1-P^{k}\right)}}$

The ASN, C(i, f) has been simulated and provided in Table 3 and Table 4 for various values of $\mathrm{f}$.

Table. 3 Optimum cost and ASN using SkSP-2 when $\mathrm{i}=4$,

$$
\mathrm{k}=1, \mathrm{n}=20, \mathrm{c}=1
$$

\begin{tabular}{|l|c|c|c|c|c|c|c|}
\hline $\mathrm{p}$ & $\mathrm{P}$ & $\begin{array}{c}\text { ASN } \\
\mathrm{f}=1 / 2\end{array}$ & $\mathrm{C}(\mathrm{i}, \mathrm{f})$ & $\begin{array}{c}\text { ASN } \\
\mathrm{f}=1 / 3\end{array}$ & $\mathrm{C}(\mathrm{i}, \mathrm{f})$ & $\begin{array}{c}\text { ASN } \\
\mathrm{f}=1 / 4\end{array}$ & $\mathrm{C}(\mathrm{i}, \mathrm{f})$ \\
\hline 0.00002 & 0.999 & 10 & 0.025 & 6 & 0.025 & 5 & 0.025 \\
\hline 0.0001 & 0.999 & 10 & 0.026 & 6 & 0.026 & 5 & 0.026 \\
\hline 0.002 & 0.999 & 10 & 0.035 & 6 & 0.035 & 5 & 0.035 \\
\hline 0.003 & 0.998 & 10 & 0.04 & 6 & 0.04 & 5 & 0.04 \\
\hline 0.004 & 0.997 & 10 & 0.045 & 6 & 0.045 & 5 & 0.045 \\
\hline 0.005 & 0.995 & 10 & 0.05 & 6 & 0.05 & 5 & 0.05 \\
\hline 0.006 & 0.993 & 10 & 0.055 & 6 & 0.055 & 5 & 0.055 \\
\hline 0.010 & 0.983 & 10 & 0.075 & 6 & 0.075 & 5 & 0.075 \\
\hline 0.011 & 0.979 & 10 & 0.08 & 6 & 0.08 & 5 & 0.08 \\
\hline 0.012 & 0.975 & 10 & 0.085 & 6 & 0.085 & 5 & 0.085 \\
\hline 0.013 & 0.972 & 10 & 0.09 & 6 & 0.09 & 5 & 0.09 \\
\hline 0.015 & 0.963 & 10 & 0.1 & 6 & 0.1 & 5 & 0.1 \\
\hline 0.017 & 0.954 & 10 & 0.11 & 6 & 0.11 & 5 & 0.11 \\
\hline 0.018 & 0.949 & 10 & 0.115 & 6 & 0.115 & 5 & 0.115 \\
\hline
\end{tabular}

Table.4 Optimum cost and ASN using SkSP-3 when $i=4$, $\mathrm{k}=1, \mathrm{n}=20, \mathrm{c}=1$

\begin{tabular}{|l|c|c|c|c|c|}
\hline$p$ & $P$ & $\begin{array}{c}\text { ASN } \\
\mathrm{f}=1 / 5\end{array}$ & $\mathrm{C}(\mathrm{i}, \mathrm{f})$ & $\begin{array}{c}\text { ASN } \\
\mathrm{f}=1 / 10\end{array}$ & $\mathrm{C}(\mathrm{i}, \mathrm{f})$ \\
\hline 0.00002 & 0.999 & 4 & 0.025 & 2 & 0.025 \\
\hline 0.0001 & 0.999 & 4 & 0.026 & 2 & 0.026 \\
\hline 0.002 & 0.999 & 4 & 0.035 & 2 & 0.035 \\
\hline
\end{tabular}

\begin{tabular}{|c|c|c|c|c|c|}
\hline 0.003 & 0.998 & 4 & 0.04 & 2 & 0.04 \\
\hline 0.004 & 0.997 & 4 & 0.045 & 2 & 0.045 \\
\hline 0.005 & 0.995 & 4 & 0.05 & 2 & 0.05 \\
\hline 0.006 & 0.993 & 4 & 0.055 & 2 & 0.055 \\
\hline 0.010 & 0.983 & 4 & 0.075 & 2 & 0.075 \\
\hline 0.011 & 0.979 & 4 & 0.08 & 2 & 0.08 \\
\hline 0.012 & 0.975 & 4 & 0.085 & 2 & 0.085 \\
\hline 0.013 & 0.972 & 4 & 0.09 & 2 & 0.09 \\
\hline 0.015 & 0.963 & 4 & 0.10 & 2 & 0.10 \\
\hline 0.017 & 0.954 & 4 & 0.11 & 2 & 0.11 \\
\hline 0.018 & 0.949 & 4 & 0.115 & 2 & 0.115 \\
\hline
\end{tabular}

\section{RESULTS AND DISCUSSION}

\section{Numerical Illustration:}

Let the number of units to be inspected is under SkSP-2 with the single sampling plan as reference plan $n=20, c=1$, where $\mathrm{i}=4$ and $\mathrm{f}=0.25$. From the Table 2 , assuming that the unit cost of inspection is $c_{1}=0.25, c_{2}=1, c_{3}=5$ and $p=0.01$ then $\mathrm{ASN}=5$ and $\mathrm{C}(\mathrm{i}, \mathrm{f})=0.0304$. Suppose a lot size $\mathrm{N}=1000$ in which number of units to be inspected using the single sampling plan as the reference plan $n=20, c=1$, where $i=4$ lots and $\mathrm{f}=0.3$, then $\mathrm{ASN}=6$ and $\mathrm{C}(\mathrm{i}, \mathrm{f})=0.043$. The behavior of the cost function (11) between these two plans are $\delta \mathrm{C}(\mathrm{i}, \mathrm{f})=0.043-0.0304=0.0126$.

As $\delta \mathrm{C}(\mathrm{i}, \mathrm{f})>0$, the partial inspection in which each lot is inspected with probability of acceptance $\mathrm{P}$ is optimal. Here $\mathrm{C}(\mathrm{i}, \mathrm{f})$ is an increasing function of $\mathrm{f}$ and $\mathrm{p}$. The cost remains same and has least difference for the respective sampling fraction of lots with the same incoming quality although the $f$ value changes. Considering the SkSP-2 and SkSP-3, the distribution of the cost $\mathrm{C}$ is degenerate distribution as their variance is zero. So the optimal value of clearance number i depends on the incoming defective $\mathrm{p}$ and various costs parameters includes in the inspection.

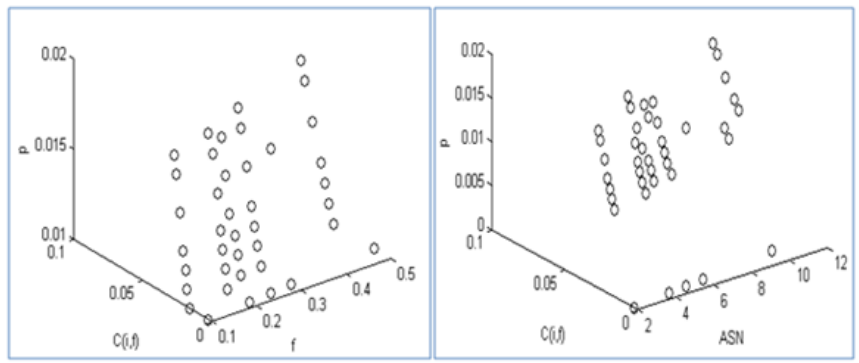

Figure 3. The cost function of SkSP-2 when $i=4, n=20, c=1$ for various values of $f$ and $A S N$. 

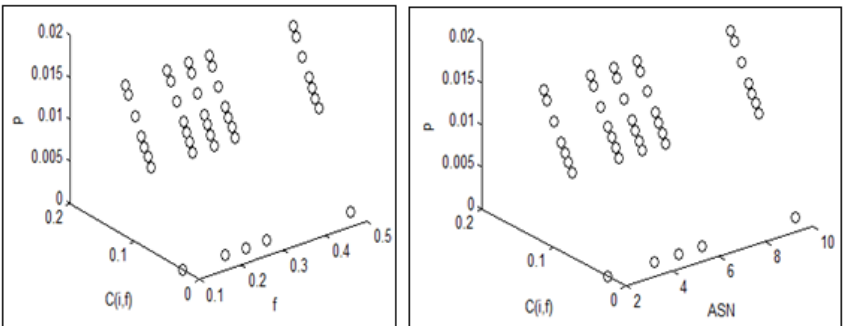

Figure5. The cost function of SkSP-3 when $i=4, n=20, c=1$ for various values off and ASN.

Figure 3 and 5 gives the complete picture how the plan works for the optimum cost and it explains, as the percentage of incoming defective increases the cost also increases. Also shows when the average sample number and sampling fraction increases the cost also increases. But the cost function is economically optimal for $\mathrm{p}=0.01$, the steady state average unit cost is 0.03 . However, Skip-lot sampling plan favors the producer and also be safeguard to the customer from accepting the unsatisfactory lot.

\section{CONCLUSION}

An attempt made in this paper to scheme the GERT model to optimize costs for the Skip lot sampling plans. The w-function helps to obtain cost information eliminates the need for making assumptions about the distribution of cost on inspection which exists in each stages of screening inspection, in partial inspection and also after the delivery of the product to the customer. Keeping i fixed and $f$ varies, the difference in the cost function is greater than zero suggest that the partial inspection is optimal with reference to the proportion defective. Thus Skip-lot sampling plan-2 and plan-3 reduces inspection effort and also it is a costeffectively optimal through GERT. This skip-lot standard provides an inducement for distributors of high quality products to maintain excellent quality levels and helps to reduce the cost of inspection with high quality goods. This proposed model can be extended to other sampling plans, switching rules based on economic design of plan-type situation. The tables has been simulated for varies values of clearance number and sampling fraction which would be the tailor-made use of decision making by the producer.

\section{REFERENCES}

[1]. S. Balamurali, C.H. Jun, "A new system of skip-lot sampling plans having a provision for reducing normal inspection", Applied Stochastic Models in Business and Industry. Vol.27, Issue 3, pp. 348-363, 2011.

[2]. S. Chakraborthy, U. K. Rathie, "Analysis of inspection error through GERT”, Sankhya series B, Vol.51, Issue 1, pp.125-133. 1989.

[3]. C.H. Chen, C.Y. Chou, "Economic design of continuous sampling plan under linear inspection cost", Journal of Applied Statistics, Vol. 29, Issue 7, pp.1003-1009, 2002.

[4]. H.F. Dodge, H.G. Romig, "A method of sampling inspection", Bell System Technical Journal, 8: 613-631, 1929.
[5]. H.F. Dodge, "A sampling inspection plans for continuous production", Annals of Mathematical Statistics, Vol. 14, pp.264279. 1943.

[6]. H.F. Dodge, "Skip-lot sampling plan", Industrial Quality Control, Vol.11, Issue 5, pp. 3-5, 1955.

[7]. H.F. Dodge, R L. Perry. "A system of skip-lot plans for lot-by-lot inspection", American Society for Quality Control Technical Conference Transactions, Chicago, Illinois, pp. 469-477, 1971.

[8]. G. Shankar, "GERT analysis of sampling plan for system reliability", Microelectronics Reliability, Vol. 28, Issue 1, pp. 2325, 1988.

[9]. A. Golub, "Designing Single Sampling Inspection Plans when the sample size is fixed", Journal of American Statistical Association, Vol. 48, Issue 262, pp. 278-288, 1953.

[10]. A. Haji, R. Haji, "The optimal policy for a sampling plan in continuous in terms of the clearance number", Computers and Industrial Engineering, Vol. 472, Issue 3, pp. 141-147, 2004.

[11]. C. Kandasamy, K. Govindaraju, "Selection of CSP-T plan", Communications in Statistics: Simulation and Computation. Vol. 22, Issue 1, pp. 265-283, 1993.

[12]. T.Y. Lin, "Optimal inspection policy for CSP-T with return cost using GERT". Journal of the Chinese Institute of Industrial Engineers. Vol. 25, Issue 6, pp. 446-456, 2008.

[13]. S.J. Mason, "Feedback theory-Some properties of Signal Flow Graphs". Proceedings of the I.R.E, Vol. 41, Issue 9, pp.1144-1156, 1953.

[14].H. Ohta, S. Kase, "GERT Analysis of Least-cost Testing Sequence", Journal of the Operational Research Society, Vol. 31, Issue 9, pp. 855 - 859, 1980.

[15]. H. Ohta, S. Kase, "GERT analysis of the Dodge-Romig sampling Inspection plan", Technometrics, Vol. 19, Issue 3, pp. 249-257, 1977.

[16]. H. Ohta, "GERT analysis of chain sampling inspection plans". Bulletin of University of Osaka prefecture. Series. A Vol. 27, Issue 2, pp. 167-174, 1978.

[17]. R.L. Perry,. "Skip-lot sampling plans". Journal of Quality Technology. Vol. 5, Issue 3, pp.123-130, 1973.

[18]. K. PradeepaVeerakumari, R. Resmi, "Designing optimum plan parameters for continuous sampling plan of type (CSP-2) through GERT analysis". Journal of Statistics and management Systems, Vol. 19, Issue 2, pp. 303-311, 2016.

[19]. K. Pradeepa Veerakumari, S. Azarudheen, "Evaluation of Single Sampling Plan under the Conditions of Intervened Poisson distribution", Communications in Statistics- Simulation and Computation, pp.1-9, 2017.

[20].A.A.B. Pritsker, "GERT: Graphical Evaluation and Review Technique”, Memorandum RM-4973-NASA, RAND Corporation, NASA, California, Vol. 21, Issue 8, 1966.

[21]. S.M. Ross, "Stochastic processes", 2nd edition, New York: Wiley. 1996.

[22]. G. Shankar, B.N. Mohapatra, "GERT analysis of Dodge's CSP-1 continuous sampling plan", Sankhya, Vol. 56, Issue 3, pp. 468478, 1994.

[23]. E.G. Schilling, D.V. Neubauer, Acceptance Sampling in Quality Control. BocaRaton: CRC Press. 2008.

[24]. V. Soundararajan, R. Vijayaraghavan, "A new system of skip-lot sampling inspection plans of type SkSP-3", Quality for progress and Development, India: Wiley Eastern. 1989.

[25]. R. Vijayaraghavan, "Design and evaluation of skip-lot sampling plans of type SkSP-3", Journal of Applied Statistics, Vol. 27, Issue 7, pp. 901-908, 2000.

[26]. S. Vispute, J.R. Singh, "Economic Effect on Variables Sampling Plans Under Second Order Auto-Correlation", International Journal of scientific research in Mathematical and Statistical Sciences, Vol. 1, Issue. 2, pp.1-15, 2014. 


\section{AUTHORS PROFILE}

Ms. Dr. K. Pradeepa Veerakumari pursued M.Sc., and Ph.D., Statistics from Bharathiar University, Coimbatore in 2004 \& 2009. She is currently working as Assistant Professor in Department of Statistics from Bharathiar University, Coimbatore since 2011. She is a member of ISPS, IISA since 2011 and Life member of ISPS since 2011. She has published

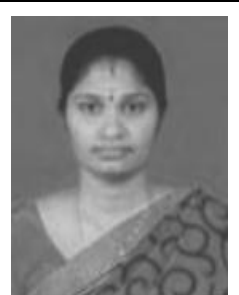
more than 20 research papers in reputed international journals including Thomson Reuters (SCI/SCI-E \& Web of Science, Scopus, and Google Scholar) and it's also available online. Her main research work focuses on Statistical Quality Control, Neural Network, Bayesian sampling and Expert system. She has 9 years of teaching experience and 14 years of research experience.

Ms. M. Kokila is pursuing her Ph.D. in the Department of Statistics, Bharathiar University, Coimbatore.

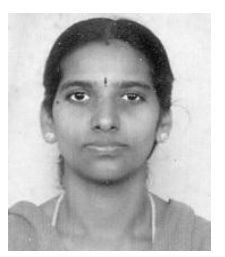

